\title{
Challenges of participatory-deliberative governance in the era of social media digitalisation
}

\section{Mariuss cepcaýśshi}

Abstract: Question of public involvement in urban development processes grows to be among the major contemporary issues of new urban governance. Local powers, traditionally based on the elected bodies (the council and the mayor) is recently being challenged by growing, often unstructured and informal urban movements. New powers have been renegotiating supremacy relations, often using social media and digital tools. The same time digital tools are used by municipalities to expand public participation. Direct participation in urban management evolve to be a basic civic right, but it is seldom correlated with responsibilities and consequences of common, especially digital, decisions. New apps and programs create many opportunities for public participation, but social media often lack broader consideration, compromise and conciliation. Simplistic digital participation can be easily fuelled by internet ignorance, expertise relativism or 'balanced routine'.

Keywords: governance, democracy, participation, deliberation, hybridisation, social media, planning, slacktivism, agnotology

\footnotetext{
* Spatial Management Department, University of Gdańsk, Poland mariusz.czepczynski@ug.edu.pl
} 


\section{Urban responsibilities and practices}

Establishing a functioning society from a community of varying and erratic individuals is a difficult task, though carried out since the beginning of civilization. It requires to tame unwanted instincts, enhanced by socialization and conversion into a communally acceptable form (Freud, 2002). Urbanisation is a result of continuing negotiations between people, their own good and common public good. Nawratek (2008) says that the city is the idea of a public space in which people live together, consider and decide together about all that concerns their common interests. Society, in particular the urban postmodern society, does not exist as a continuum, but on the contrary, can be seen as a multiplicity of autonomous flexible logics, orders, value systems. Conceptually urban condition can be seen as 'temporary relation of interdependent elements within a responsive and interacting system'. The boundaries of such system are dynamic and require constant reassessment and re-definition, subject to the applied point of view (Zector Architects, 2015). Residents of a modern metropolis are at the same time afraid of restrictions of personal freedom, and dreaming of being a part of a coherent community (Czepczyński, 2014). Most people in the depths of their souls do not want freedom, because freedom is combined with responsibility, and responsibility scares most of the people (Freud, 2002). Nevertheless benefits and needs of the community became a priority over the needs of the individual, resulting in the formation of compromising social mechanisms or governance. Urbanity is based and depends on defuse and dissemination of constant compromises between strangers, their lifestyles, believes, expectations and hopes. Urban institutions and rituals have long civic tradition to accommodate and assimilate various differences within social, mental, cultural, economic and physical infrastructures.

Liquid post-modernity in which we live - with its individualisation, distribution of codes of ethics, weakening authority, their multiplicity and lack of a spiritual power, which would invalidate other voices - is both great opportunity and threat to our democracies (Bauman, 2011). Our moral life is 
ruled by a code of ethics aspiring to make it widely assumed, but it is hardly about morality, but about conformity. Morality in fact does not rely on a code of faithfulness, but on responsibilities for other people. Levinas (1991) states that being moral is being aware of social responsibilities. Being together with others, as a part of a community, requires giving up part of own rights and desires, and obliges a certain, often considerable self-sacrifice and self-restraint.

The quintessence of a city is about social capital and necessary infrastructure capital to maintain and facilitate cohesive communal urban life to make a bunch of strangers living together feasible. The most important value of the city, Greenberg (1995) believes, is its network of human relations built on exchange - the full range of voluntary interactions, whether commercial, social, intellectual, or the like. Proximity and density of spaces impose both strategic and daily compromises and interchanges. Cities, since the beginning of civilisations, have been based on infrastructures. Alongside vital technical and social infrastructure, cities are also based on mentastructure (Bharadwaj, 2012). It is most typical cultural infrastructure, aimed to enhance needs, ambitions, responsibilities, obligations, trusts, and wishes of the aspiring urban society. Mentastructure, just like any infrastructure, has its material feature - it is based on buildings and institutions - museums, houses of culture, city halls, courts of justice, shrines, and its materiality determines or facilitates its social and cultural significance. Cities cannot function without civic mentastrucure, its self-organisation and mechanisms of power.

The effectiveness of city management relies on a relationship between the existing procedures their contractors and expectations of residents. Urban planning is a material incarnation of a civic mentastrucure. The traditional practice of long term master-planning and linear processing is no longer adequate to deal efficiently with the complexity, pace and scale of issues imposed by the built environment today. An adaptive and integrated planning instruments must be implemented. Furthermore an increase of complexity of proposals through multitasking, hybridity and methods of curative manipulation can secure a high level of potential influence, enabled through detailed knowledge 
of 'symbiotic' interests of various urban stakeholders (Zector Architects, 2015).

\section{Democracy and participation in post-modern urban governance}

Contemporary cultural and technological transformations challenge everyday lifestyles, practices, and policies. It is impossible to continue to cultivate an urban management policy in which we grew up - it must be a new policy and a new, post-modern democracy. Nowadays it is usually easier to gather people around public goods - ecology, green energy, public spaces - than around conventionally regarded group interests or traditional social classes (Inglehart, 1995). Equality takes on a special dimension in modern cities; a person should have a sense of purpose and meaning of life, participation and co-own fate. The question of city ownership and civic engagement is being raised frequently (de Lange and de Waal, 2013). Representative democracy seems no longer meet the emerging co-governance pleas. Elected representatives and city managers have to face dynamically changing social expectations. Modern cities are too large, too diverse and open, that top-down control and management of each aspects of urban life becomes uncomprehensive. An opportunity for urban development, in particular those most creative and at the same time unruly communities is collective, voluntary self-control. The city mechanically ruled from above, by laws and decrees, arbitrary visions and decisions of local besserwissers becomes an urban history (Leadbreater and Miller, 2004).

Democracy means above all self-rule, but because it is practically impossible to expect that such self-rule can be expressed by all, everywhere, on all matters and constantly, it must create conditions so that this may happen at least on some issues, and at least some of the time (Florida, 2013). It is necessary to guarantee to all citizens the possibility that self-rule may be practiced on at least some of their common interests. Only through this participative practice, Barber (1984) argues, it is possible to maintain the meaning and function of citizenship alive in each citizen, a notion that is destined to atrophy if participation is entrusted only to the 
electoral mechanisms of legitimacy and delegation. In Barber's view, when we delegate, not only do we cede power: we also lose the very sense of our civic autonomy. While the liberal view understands 'freedom and power as antonyms, each defined (analytically) by the absence of the other' (Barber, 1984, p. 35), and propose an image of Man as an 'inactive, nonparticipating, isolated, uninterfering with, privatized, and thus free' being (Barber, 1984, p. 36). Strong democracy, on the contrary, entails a view of freedom as a full manifestation of an individual's autonomy (and thus of his power), immersed in a dimension of collective and communitarian life. Freedom, therefore, is self-ownership, self-determination, self-realization of human potentialities (Florida, 2013). The reconstruction of modern democracy must rely on the strength of local democracy; pragmatic, visible, transparent and useful for people. People's power to the city has been taking more and more direct form in the recent years (Czepczyński, 2014).

Participatory democracy emphasizes the broad involvement of constituents in the direction and operation of political systems. Etymological roots of democracy (Greek demos and kratos, or 'rule of the commoners') imply that the people are in power and thus that all democracies are participatory. Urban governance has a history of direct participation of 'the commoners'. Beyond monarchs, mayors and councillors there have always been numerous more or less formal bodies and institutions, participating in city planning and development. For centuries parish councils, guilds, societies, cartels, companies and many others had been shaping and re-shaping our cities. Only the $20^{\text {th }}$ century strict planning rules and laws limited various forms of popular social participations in urban development, leaving all of the power to the bureaucratic hands and minds of urban planners.

The term 'participatory democracy' has been introduced by Arnold S. Kaufman (1960) in a paper Human Nature and Participatory Democracy, on the topic of 'responsibility'. "As a social system we seek the establishment of a democracy of individual participation, governed by two central aims: that the individual share in those social decisions determining the quality and direction of his life; that society be 
organized to encourage independence in men and provide the media for their common participation. Other principles state that:

- decision-making of basic social consequences be carried on by public groupings;

- politics be seen positively, as the art of collectively creating an acceptable pattern of social relations;

- politics has the function of bringing people out of isolation and into community, thus being a means of finding meaning in personal life;

- the political order should serve to clarify problems in a way instrumental to their solution; it should provide outlets for the expression of personal grievance and aspiration." (Hayden 2005, pp. 53-54)

The term 'participatory democracy' came into widespread use after 1962, when Students for a Democratic Society gave it a central place in its founding Port Huron Statement (Mansbridge, 1993). What the term meant then was unclear, and it became less clear afterward, as it was applied to virtually every form of organization that brought more people into the decision-making process. In a participatory democracy, political life would be based on several root principles:

- an image of Man as optimistic on the potential of human self-development; rejection of the notion that individuals are intrinsically 'incompetent' and unable to govern their common life or to deal with the issues affecting their lives with a view to the long term;

- an ideal of individual self-determination, autonomy and independence and, at the same time, an ideal of fraternity as the dominant form of social relationships: 'This kind of independence does not mean egoistic individualism: the object is not to have one's way so much as it is to have a way that is one's own', is the key-phrase in this respect;

- the idea that decision-making processes, on issues having social implications and consequences, must be conducted in public and participative ways (Mansbridge, 1983, p. 376).

'Participatory democracy' made a comeback with the New Global Movements of the late 1990s and the early 
2000s, also thanks to the renown of certain innovative experiments such as the Participatory Budget of Porto Alegre. Local and communitarian view of democracy reemerged: against the logic of a 'single thought', it was necessary to activate a 'bottom-up' social protagonism, and 'participatory democracy' was considered the tool through which a new, critical and antagonistic, subjectivity could be built. Thus, the idea of the empowerment of local societies returned to the foreground; as did the idea that local communities are capable of ruling themselves with direct forms of democracy and thus seek to regain control of their own future (Florida, 2013).

Participation can encompass a broad range of phenomena: it may be distinguished according to the sphere in which it is expressed or according to the forms it can take. It is considered that participation enables a specific form of political decision-making to be shaped and practiced. It is on this point that substantial differences in theoretical perspectives emerge, in relation to the notion of 'deliberative democracy'. These two terms cannot be equated: 'participatory democracy' is founded on the direct action of citizens who exercise some power and decide issues affecting their lives; 'deliberative democracy', instead, is founded on argumentative exchanges, reciprocal reason-giving, and on the public debate which precedes decisions (Florida, 2013). 'Deliberative democracy' sees deliberation as a step or a phase of a dialogic and discursive process for reaching decisions, which legitimate democratic institutions, and only these, must and can take. The term 'deliberative democracy' was originally coined by Joseph M. Bessette (1980) in his work Deliberative Democracy: The Majority Principle in Republican Government, but clearly influenced by works of John Rawls (1993) and Jürgen Habermas (1992).

A democratic deliberative procedure is based on public debate and reciprocal reason-giving, and may aim to attain a rational consensus or a shared solution. There are, therefore, forms and types of participation which have a deliberative inspiration, within which a more or less deliberative dimension or quality may be operating; but not all forms of deliberation are 'participative'; and not all 
forms of participation are 'deliberative'. Antonio Florida (2013) investigates the link between participation and decision, between deliberation and decision; and - above all the greater or lesser immediacy or nonimmediacy of these relations; and the connection (whether convergent and/or conflictual) between a democratic legitimacy of decisions, deriving from public and inclusive deliberation, and a democratic legitimacy based upon institutional procedures proper to a constitutional state. Jane Mansbridge (1980) in her book Beyond Adversary Democracy suggests a new pair of theoretical categories: unitary vs. adversary democracy and introduces an empirical perspective.

Bua (2017) introduces the concept of 'participatory-deliberative processes' (PDP) to engage citizens in deliberative forms of participation, oriented towards influencing public policy making. They can reduce the distance between state and non-state actors by allowing citizens to explore preferences and influence policy through public participation and deliberation (Burgess and Chilvers, 2006). They have been valued for their potential to increase the reflexivity and responsiveness of policy making (Hoppe, 2010). Participatory-deliberative processes have been criticised on the grounds of their poor scalability and low impact - especially when operating at high tiers of governance. Unlike direct democratic processes that aggregate millions of preferences through voting, PDPs are predicated on deliberative interactions between participants, and are often oriented towards consensus. For this reason they face problems of 'scalability', meaning that the impact that they can claim to have on policy making decreases as scale increases (Bua, 2017). Suspicions abound that public authorities tend to 'cherry pick' recommendations that cohere with decisions that are already made and analysts have argued that elites might accept PDPs in order to pre-empt more contentious forms of political action (Hoppe, 2011). This has led sympathetic critics to argue that PDPs are often limited to local issues of little strategic importance (Wainwright, 2003), sceptics argue that they offer little more than 'therapeutic' (Chandler, 2001) forms of participation that do little in way of engaging real power structures (Davies, 2012). 


\section{Social melia participative solltions}

The world is changing at a speed we could never have imagined before. The social web and mobile technologies have accelerated the rate at which relationships develop, information is shared and influence takes hold. People now use social technology to help shape the world's economy and culture. Social media is one of the most important global leaps forward in recent human history. It provides for selfexpression and promotes mutual understanding. It enables rapid formation of networks and demonstrates our common humanity across cultural differences. It connects people, their ideas and values, like never before (Omidyar, 2014). Facebook has taught us new ways to communicate and collaborate through features like feeds, profiles and groups. At the same time, smartphones and tablets provide mobile and instantaneous access to information from any location. Connected individuals have rallied crowds, created vast audiences and toppled political establishments by communicating their message through social networks (Benioff, 2012). New communication technologies and improved accessibility to high-speed networks make large amounts of data instantly available and minimise the time to make major decisions. The results have increased levels of economic and political dynamics but also exclusion and conditions of uncertainty at the regional and local scale.

In today's cities our everyday lives are shaped by digital media technologies such as smart cards, surveillance cameras, quasi-intelligent systems, smartphones, social media, location-based services, wireless networks, and so on. These technologies are inextricably bound up with the city's material form, social patterns, and mental experiences. As a consequence, the city has become a hybrid of the physical, social and the digital. Digital media and culture allow citizens to engage with, organize around and act upon collective issues and engage in co-creating the social fabric and built form of the city. The role of new media technologies in urban design shifts from an infrastructural to a social point of view, or from 'city management' to 'city making' (de Lange \& de Waal, 2013). Participatory democracy strives to create opportunities for all members 
of a population to make meaningful contributions to decision-making, and seeks to broaden the range of people who have access to such opportunities. Since so much information must be gathered for the overall decision-making process to succeed, technology may provide important forces leading to the type of empowerment needed for participatory models, especially those technological tools that enable community narratives and correspond to the accretion of knowledge. Effectively increasing the scale of participation, and translating small but effective participation groups into small world networks, are areas currently being studied. Other advocates have emphasised the importance of face to face meetings, warning that an overreliance on technology can be harmful.

There is a number of promising developments, resulting from the social - digital urban hybridisation. Many of them result from the rise of data commons, engagements and sense of place, creation of networked public and numerous DIY urban design and actions (de Lange \& de Waal, 2013). Many local authorities, with a help of creative technologies and smart applications, invite citizens to participate in the decision making process. City authorities of Californian city of Santa Monica are trying to gauge public opinion on everything from street furniture and parking, to murals and market stalls for their forthcoming urban plan, using a digital tool modelled on Tinder, a dating app. CitySwipe (www. cityswipeapp.com) presents local residents with images of potential scenarios and simple yes/no questions, encouraging people to swipe through the options, as if assessing prospective partners. For the time being, it's fairly basic: a photo of some street art appears with a caption asking: "Do you want more of this?" The questions move on to attitudes towards walking, bike lanes, housing and beyond. It makes the consultation process quite effortless, but also rather shallow. Research undertaken by the Future Cities Catapult (futurecities.catapult.org.uk), a government-funded organisation dedicated to exploring solutions to urban issues, has uncovered a wealth of digital innovations that could lead towards a more data-driven planning system, making proposals more transparent and outcomes more certain for all parties involved (Wainwright, 2017). 
The snappily named Greater Manchester Open Data Infrastructure Map (mappinggm.org.uk) aggregates everything from water and transport networks to property prices and brownfield land, offering a total overview of the city's physical, social, and green infrastructure. An additional map shows proposed development plots, compiling those allocated by the council with sites suggested by residents and developers, so everyone can see what's going on in their area. In London, start-up company Urban Intelligence (www.urbanintelligence.co.uk) has turned its attention to how the innumerable different planning policies that regulate any particular site can be made more intelligible, bringing the contents of disparate policy documents together in one place. Their interactive platform collates and digitises national and neighbourhood policies, allowing you to click on a place on the map and see everything relevant in one go. US platform Flux Metro (metro.flux.io) has taken the idea a step further and built a 3D model that integrates zoning information with financial viability algorithms, to predict the likely profitability of a scheme in any given scenario. It allows developers to visualise a site's context and constraints, including building heights and shadows, to inform what might be possible to build. As the nascent UrbanPlanAR platform (urbanplanar.com) allow 3D models of new developments to be superimposed onto their real-world sites, letting local residents walk around future proposals and feel their true impact (Wainwright, 2017).

\section{Hyper media and the damage of deliberation}

By now, we are all aware that social media has had a tremendous impact on our culture, in business, on the worldat-large. Social media websites are some of the most popular haunts on the internet. They have revolutionized the way people communicate and socialize on the Web. Hyper media create a sense of unambiguous simulacra of real spaces, places, relations, networks, problems, but the virtual relationships seem to oblige less, or are taken by most of us less seriously. The 'participator', well hidden behind a smartphone or laptop screen remains often anonymous or at a safe 
distance, and for many virtual opinions remain much more virtual than real. Despite of new modes and technological advantages, the most popular model of active participation in local planning and development processes has been for decades based on a few rudimentary attitudes, starting from NIMBY (Not In My Back Yard), BANANA (Build Absolutely Nothing Anywhere Near Anything) to CAVE (Citizens Against Virtually Everything). Anxiety for change makes most citizens active participants in urban planning (Czepczyński \& Szołucha, 2017). Responsible civic relation with place and the city shall not be built upon casual, onetime Tinder-like clicks. All the smart media are designed to mediate between humans, who take all the responsibility of the mediation process.

In April 2016, Mark Zuckerberg, chief executive of Facebook, addressed a room of developers about the importance of his social network. Facebook, he said, has the power to bring people together who might otherwise never have the chance to meet. 'The internet has enabled all of us to access and share more ideas and information than ever before,' he said. 'We've gone from a world of isolated communities to one global community, and we are all better off for it.' But that's not what has happened. Zuckerberg's idealism is belied by his desire to duck responsibility for mediating the content of his site. On Facebook, the political divide has only been entrenched further. The internet once offered outlets we could use to understand one another. But they are rapidly disappearing (Wortham, 2016). A year later, in an interview with the BBC, Zuckerberg quotes Abraham Lincoln who spoke of acting 'in concert', and talks about 'spiritual needs', civic engagement and says that many people have 'lost hope for the future' (Ahmed, 2017).

The loosing hope is, to some extent, related to hyper social media. Many introverts and socially reclusive users place too much emphasis on virtual interaction, and ignore the real world outside, while some make the sense of life by trolling and hating others' posts (Ta 2014). There is a growing, specifying 'click-o-mania' and the alleged power of the 'LIKE', instead of real action and support. In our information-rich world, activist and advocacy groups trying to get attention for particular causes increasingly rely on social 
media as a means of building support for their causes. Such forms of advocacy, particularly those related to social media, are often derisively referred to as 'slacktivism' or 'armchair activism.' These activities pose a minimal cost to participants; one click on Facebook or retweet on Twitter and the slacktivist can feel that he or she has helped to support the cause. Slacktivists don't have to move from behind the screens of their electronic devices (Seay, 2014). Many seem to be lost in virtual (un)reality, where actions and activities are limited to clicks and swaps, usually without any major consequences. Facebook activists are often only facebookly conscious, every so often unrelated to real people, places, time and contexts. It seems that urban societies are quickly passing another limes or cultural border, evolving to become, on one hand more democratic and open, but on the other hand, more able to accept certain dictatorship of a narrow majority, at least on national levels. Social media became profitable, but hardly controlled hyper media, overloaded with myriads of post-truths and other, including useful, pieces of information. Trust and sincerity has been lost by clouds of post-truth information shares, flows of emoticon emotions, which seemed to dominate over rational reasoning. Hundreds of parallel info-bubbles enhance hermetic hyper-societies or likeabilities, while the relation between opposite spheres is based on misinterpretation, mistrust, ignorance, which leads to hate.

Deliberate propagation of ignorance or agnotology, as named by Robert N. Proctor (Proctor \& Schebinger, 2008), seems to a growing as major thread to democratic procedures. It comes from agnosis, the neoclassical Greek word for ignorance or 'not knowing', and ontology, the branch of metaphysics which deals with the nature of being. Agnotology is the study of wilful acts to spread confusion and deceit, usually to win favour. Ignorance can often be propagated under the guise of balanced debate. The common idea that there will always be two opposing views does not always result in a rational conclusion. This 'balance routine' allows to claim that there are two sides to every story, that 'experts disagree' - creating a false picture of the truth, hence ignorance. Facebook founder Mark Zuckerberg admitted himself that fake news, polarised views and 'filter bubbles' were 
damaging 'common understanding'. In a call to action, Zuckerberg says that people must not 'sit around and be upset', but act to build 'social infrastructures' (Ahmed, 2017). 'We live in a world of radical ignorance, and the marvel is that any kind of truth cuts through the noise', says Proctor (after Kenyon, 2016). But the very same Zuckerberg says also that 'In a free society, it's important that people have the power to share their opinion, even if others think they're wrong. Our approach will focus less on banning misinformation, and more on surfacing additional perspectives and information, including that fact checkers dispute an item's accuracy' (Ahmed, 2017). Even though knowledge is 'accessible', it does not mean it is accessed. Ignorance spreads when firstly, many people do not understand a concept, context or fact and secondly, when special interest groups - like a commercial firm or a political group - then work hard to create confusion about an issue. It's not just about the facts, it's about what is imagined to flow from and into such facts' (Kenyon, 2016).

\section{Condusions}

Real democracy and citizenship are more than exhaustive legislation and regulations. Elected officials, technocrats and citizens must work together daily. Constructive answerable participation of civil society can maintain a constant pace indefinitely. The city of the future shall be agile and responsive. The most effective way to conveying information to and within a working group is face to face conversation, as a base of deliberation and compromise. For efficiency reasons at a larger scale, the use of the internet is recommended. A constant attention to excellence in political anticipation, transparency and good design in the implementation enhance agility in politics. Simplicity - the art of maximizing the amount of work not necessary to do - is essential (Bruno, 2011). Those who respond and are responsible for the city, have to jointly ensure both the quality of the space, as well as their identity. People abandon places without properties, anchoring where they can find something of value for themselves, intriguing, something to identify with and enrich 
(Bell \& de-Shalit, 2011). The only salvation in an era of globalization and homogenization, as well as the best protection against extremes of nationalism is the town's ethos, characteristic spirit, belief in their own community identity. Responsible local community demonstrates strong magnetic ethos of the place, worth fighting for. In contemporary digitalized and fragmented cities and societies, prolific deliberation becomes more and more difficult, despite all the technological assistance and possibilities. Civic urban mentastructe, based on trust, responsibilities and righteousness is being challenged by waves of particularism, hypocrisy, isolationism, xenophobia, and, probably the most dangerous of them all - ignorance.

David Dunning (2003) warns that the internet is helping propagate ignorance - it is a place where everyone has a chance to be their own expert, he says, which makes them prey for powerful interests wishing to deliberately spread ignorance. Mark Zuckerberg confesses that we live in the world, where 'polarisation and sensationalism' undermined 'common understanding' (Ahmed, 2017). While some smart people will profit from all the information now just a click away, many will be misled into a false sense of expertise (Kenyon, 2016). Dunning says that his worry is 'not that we are losing the ability to make up our own minds, but that it's becoming too easy to do so. We should consult with others much more than we imagine. Other people may be imperfect as well, but often their opinions go a long way toward correcting our own imperfections, as our own imperfect expertise helps to correct their errors'. In his classic work, Arnold Kaufman (1960) states that within participatory democracy opposing views should be organized so as to illuminate choices and faciliate the attainment of goals, but social media - which deals in short, often aggressive, messages - had been part of the problem. 'In some places it could over simplify important and complex topics and may push us to have over simplified opinions of them', pleads Zuckerberg (after Ahmed, 2017). De-contextualisation, certain anonymity, lack of responsibility and respect for others, together with erosion of knowledgeable establishments and the rise of ignorant, home-grown pseudo-expert challenges digital democracy to its very roots. 


\section{References}

Ahmed, K. (2017). Zuckerberg: My Facebook manifesto to re-boot globalisation. BBC News, http://www.bbc.co.uk/news/business-38998884, 16.02.2017.

Barber, B. (1984). Strong Democracy. Participatory Politics for a New Age. Berkeley: University of California Press.

Bauman, Z. (2011). Culture in a Liquid Modern World. Cambridge: Polity.

Bell, D. A., de-Shalit, A. (2011). The Spirit of Cities: Why the Identity of a City Matters in a Global Age. Princeton: Princeton University Press.

Benioff, M. (2012). Welcome to the social media revolution, BBC News, 11.05.2012, http://www.bbc.com/news/business-18013662, accessed 16.02.2017.

Bessette, J. M. (1980). Deliberative Democracy: The Majority Principle in Republican Government. In: R.A. Goldwin, W.A. Schambra (Eds.), How Democratic Is the Constitution? Washington and London: American Enterprise Institute for Public Policy Research.

Bharadwaj, V. (2012). Cultural jewels in the Gulf. International Herald Tribune, 3(21), 14.

Bruno, P. (2011). Manifesto for Agile Development of Democracy. http://agile-democratie.blogspot.com/p/mdad-manifesto-en. html, accessed 16.02.2017.

Bua, A. (2017). Scale and Policy Impact in Participatory and Deliberative Democracy: Lessons from a Multi-Level Process. Public Administration, 95(1), 160-177.

Burgess, J. Chilvers, J. (2006). Upping the Ante: A Conceptual Framework for Designing and Evaluating Participatory Technology Assessments. Science and Public Policy, 33(10), 713-728.

Chandler, J.A. (2001). Local Government Today. Manchester: Manchester University Press.

Czepczyński, M. (2014). (Nie)odpowiedzialni za miasto. O ograniczeniach, poszukiwaniach i nauce kompromisu między partykularnym a wspólnym dobrem. Studia KPZK PAN, 157, 6-16.

Czepczyński, M., Szołucha K. (2017). Partycypacja mieszkańców w zarządzaniu przestrzenia. In: G. Chaberek-Karwacka (Ed.), Wspótczesne uwarunkowania procesów zarzadzania przestrzenia $w$ Polsce. Gdańsk: Wydawnictwo UG.

Davies, J. (2012). Network Governance Theory: A Gramscian Critique. Environment and Planning A, 44(11), 2687-2704.

Dunning, D., Johnson, K., Ehrlinger, J., Kruger, J. (2003). Why people fail to recognize their own incompetence. Current Directions in Psychological Science, 12(3), 83-87. 
Florida, A. (2013). Participatory Democracy versus Deliberative Democracy: Elements for a Possible Theoretical Genealogy. Two Histories, Some Intersections. In: 7th ECPR General Conference, Bordeaux, 4-7 September 2013.

Freud, Z. (2002). Civilization and Its Discontents. London: Penguin. Greenberg, M. (1995). The Poetics of Cities: Designing Neighborhoods that Work. Columbus: Ohio State University Press.

Habermas, J. (1998). Between Facts and Norms: Contributions to a Discourse Theory of Law and Democracy. Cambridge, MA: MIT Press.

Hayden, T. (2005). The Port Huron Statement. The Vision Call of the 1960s Revolution. New York: Avalon Publishing.

Hoppe, R. (2010). The Governance of Problems: Puzzling, Powering and Participation. Bristol: The Policy Press.

Inglehart, R. (1995). Changing Values, Economic Development and Political Change. International Social Science Journal, 47(3), 379-403.

Kaufman, A. S. (1960). Human Nature and Participatory Democracy. In: C. J. Friedrich (Ed.), Responsibility (pp. 266-289). New York: Liberal Art Press.

Kenyon, G. (2016). The man who studies the spread of ignorance. BBC Future, 06.01.2016. http://www.bbc.com/future/ story/20160105-the-man-who-studies-the-spread-of-ignorance, accessed 15.12.2016.

Lange, M. de, Waal, M. de (2013). Owning the city: New media and citizen engagement in urban design. First Monday, 18(11). http://firstmonday.org/ojs/index.php/fm/article/view/4954/3786, accessed 15.12.2016.

Leadbeater, C. W., Miller, P. (2004). The Pro-am Revolution: How Enthusiasts are Changing Our Society and Economy. London: Demos.

Lévinas, E. (1991). Totality and Infinity. An Essay on Exteriority. Dordrecht: Kluwer.

Mansbridge, J. (1983). Beyond Adversary Democracy. Chicago: The University of Chicago Press.

Nawratek, K. (2008). Miasto jako idea polityczna. Kraków: Korporacja Ha!art.

Omidyar, P. (2014). Social Media: Enemy of the State or Power to the People? The Huffington Post, http://www.huffingtonpost.com/pierre-omidyar/social-media-enemy-of-the_b_4867421. html, accessed 15.12.2016.

Proctor, R., Schiebinger, L. (2008) (Eds.). Agnotology: The Making and Unmaking of Ignorance. Stanford: Stanford University Press.

Rawls, J. (1993). Political Liberalism. The John Dewey Essays in Philosophy. New York: Columbia University Press. 
Seay, L. (2014). Does slacktivism work? The Washington Post, 12.03.2014. https://www.washingtonpost.com/news/monkey-cage/wp/2014/03/12/does-slacktivism-work, accessed 15.12.2016.

Ta, J. Q. (2014). What Impact Has Social Media Truly Had On Society. Business 2 Community. http://www.business2community.com/social-media/impact-social-media-trulysociety-0974685\#ZvVjyc0q3PtYt0zj.99Read more at http:// www.business2community.com/social-media/impact-socialmedia-truly-society-0974685\#ZvVjyc0q3PtYt0zj.99, accessed 15.12.2016.

Wainwright, H. (2003). Reclaim the State: Experiments in Popular Democracy. London: Verso.

Wainwright, O. (2017). Tinder for cities: how tech is making urban planning more inclusive. The Guardian, 24.01.2017. https:// www.theguardian.com/cities/2017/jan/24/tinder-cities-technology-making-urban-planning-interactive, accessed 16.02.2017.

Wortham, J. (2016). Is Social Media Disconnecting Us From the Big Picture? The New York Times Magazine, 22.11.2016. https://mobile.nytimes.com/2016/11/22/magazine/is-socialmedia-disconnecting-us-from-the-big-picture.html?, accessed 15.12.2016.

Zector Architects (2015). http://www.zectorarchitects.net/urban$\mathrm{sim} /$ critical-urbanism/, accessed 15.12.2016. 